\title{
A dimensional analysis for determining optimal discharge and penstock diameter in impulse and reaction water turbines
}

\author{
A. S. Leon ${ }^{\mathrm{a}, *}$, L. Zhu ${ }^{\mathrm{b}}$ \\ ${ }^{a}$ School of Civil and Construction Engineering, Oregon State University, 101 Kearney Hall, Corvallis, OR 97331-3212, USA \\ ${ }^{b}$ Department of Civil and Environmental Engineering, Louisiana State University, 3158C Patrick F. Taylor Hall, Baton Rouge, LA \\ 70803, USA
}

\begin{abstract}
7 Abstract
8 This paper presents a dimensional analysis for determining optimal flow discharge and optimal penstock diameter when designing impulse and reaction turbines for hydropower systems. The aim of this analysis is to provide general insights 10 for minimizing water consumption when producing hydropower. This analysis is based on the geometric and hydraulic 11 characteristics of the penstock, the total hydraulic head and the desired power production. As part of this analysis, 12 various dimensionless relationships between power production, flow discharge and head losses were derived. These 13 relationships were used to withdraw general insights on determining optimal flow discharge and optimal penstock di14 ameter. For instance, it was found that for minimizing water consumption, the ratio of head loss to gross head should 15 not exceed about $15 \%$. Two examples of application are presented to illustrate the procedure for determining optimal 16 flow discharge and optimal penstock diameter for impulse and reaction turbines.
\end{abstract}

(C) 2014 Published by Elsevier Ltd.

17 Keywords:

18 Dimensional analysis, Hydropower, Impulse turbine, Optimal flow, Optimal penstock diameter, Reaction turbine

\section{Introduction}

The world energy consumption will grow by $56 \%$ between 2010 and 2040 [6]. As world population continues to grow and the limited amount of fossil fuels begins to diminish, there is an increasing demand to exploit renewable sources of energy.

In the United States, about 9\% of all energy consumed in 2012 was from renewable sources [7]. While this is a relatively small fraction of the U.S. energy supply in 2012, the United States was the world's largest consumer of renewable energy from geothermal, solar, wood, wind, and waste for electric power generation producing almost $25 \%$ of the world's total [7]. This institute also reports that in 2012,30\% of the renewable 27 energy in the U.S. was from hydropower. This means that only about $3 \%$ of all energy consumed in the 28 United States was from hydropower.

\footnotetext{
${ }^{*}$ Corresponding author

Email address: arturo.leon@oregonstate.edu. Tel.: +1 541737 2606; fax: +1 541737 3052. (A. S. Leon)
} 
Globally, hydropower accounted for $16 \%$ of all global electricity production in 2007, with other renewable energy sources totalling 3\% [5]. Hence, it is not surprising that when options are evaluated for new energy developments, there is strong impulse for fossil fuel or nuclear energy as opposed to renewable sources. However, as hydropower schemes are often part of a multipurpose water resources development project, they can often help to finance other important functions of the project [3]. In addition, hydropower provides benefits that are rarely found in other sources of energy. In fact, dams built for hydropower schemes, and their associated reservoirs, provide human well-being benefits, such as securing water supply, flood control and irrigation for food production, and societal benefits such as increased recreational activities and improved navigation [3].

Furthermore, hydropower due to its associated reservoir storage, can provide flexibility and reliability for energy production in integrated energy systems. The storage capability of hydropower systems can be seen as a regulating mechanism by which other diffuse and variable renewable energy sources (wind, wave, solar) can play a larger role in providing electric power of commercial quality [5]. While development of all the remaining hydroelectric potential could not hope to cover total future world demand for electricity, implementation of the remaining potential can make a vast contribution to improving living standards in the developing world (South America, Asia and Africa), where the greatest potential still exists [7].

Minimizing water consumption for producing hydropower is critical given that overuse of flows for energy production may result in a shortage of flows for other purposes such as irrigation or navigation. The present work was motivated when the first author was unable to find in the literature a theoretical framework for determining optimal flow discharge and optimal penstock diameter for the design of impulse and reaction turbines. Recently, Pelz [4] provided a theoretical approach for determining the upper limit for hydropower gained by a water wheel or turbine per unit width in a rectangular open-channel. This is somewhat different of impulse and reaction turbines, as in the latter turbines, the flow in the penstock is pressurized.

This paper aims to provide general insights on determining optimal flows and optimal penstock diameters when designing impulse and reaction turbines for hydropower systems. This paper is divided as follows. First, dimensionless relationships between power production, flow discharge and head losses are derived. Second, these relationships are used to withdraw general insights on determining optimal flow discharge and optimal penstock diameter. Third, examples of application for determining optimal flows when designing impulse and reaction turbines are presented. Finally, the key results are summarized in the conclusion.

\section{Dimensional analysis for optimal flow discharge, optimal head losses and optimal power}

The electric power, $P$, in Watts $(\mathrm{W})$, can be determined by the following equation:

$$
P=\eta \gamma Q\left(H_{g}-h_{L}\right)
$$

where $\gamma(=\rho \times g)$ is specific weight of water in $\mathrm{kg} /\left(\mathrm{m}^{2} \times \mathrm{s}^{2}\right), Q$ is flow discharge in $\mathrm{m}^{3} / \mathrm{s}, H_{g}$ is gross head in $\mathrm{m}, h_{L}$ is sum of head losses in $\mathrm{m}, \rho$ is water density in $\mathrm{kg} / \mathrm{m}^{3}, g$ is acceleration of gravity in $\mathrm{m} / \mathrm{s}^{2}$, and $\eta$ is overall hydroelectric unit efficiency, which in turn is the product of turbine efficiency $\left(\eta_{t}\right)$ and generator $\operatorname{efficiency}\left(\eta_{g}\right)$. In all derivations presented in this paper, it is assumed that $\eta\left(=\eta_{t} \times \eta_{g}\right)$ is constant.

For an impulse turbine (see Fig. 1), the sum of head losses can be written as

$$
h_{L}=\frac{Q^{2}}{2 g A_{2}^{2}}\left[f \frac{L}{D_{2}}+\sum k_{1-2}+k_{N}\left(\frac{A_{2}}{A_{N}}\right)^{2}\right]
$$
68 by (e.g., [1]). where $L, D_{2}$ and $A_{2}$ are length, diameter and cross-sectional area of penstock, respectively. In addition, $f$ is friction factor, $\sum k_{1-2}$ is the sum of local losses in penstock due to entrance, bends, penstock fittings and gates, $A_{N}$ is nozzle area at its exit (section 3 in Fig. 1) and $k_{N}$ is nozzle head loss coefficient, which is given

$$
k_{N}=\frac{1}{C_{V}^{2}}-1
$$


69 where $C_{V}$ is nozzle velocity coefficient. According to Dixon (2005), $C_{V}$ varies between 0.98 and 0.99 for a

70 typical Pelton turbine nozzle.

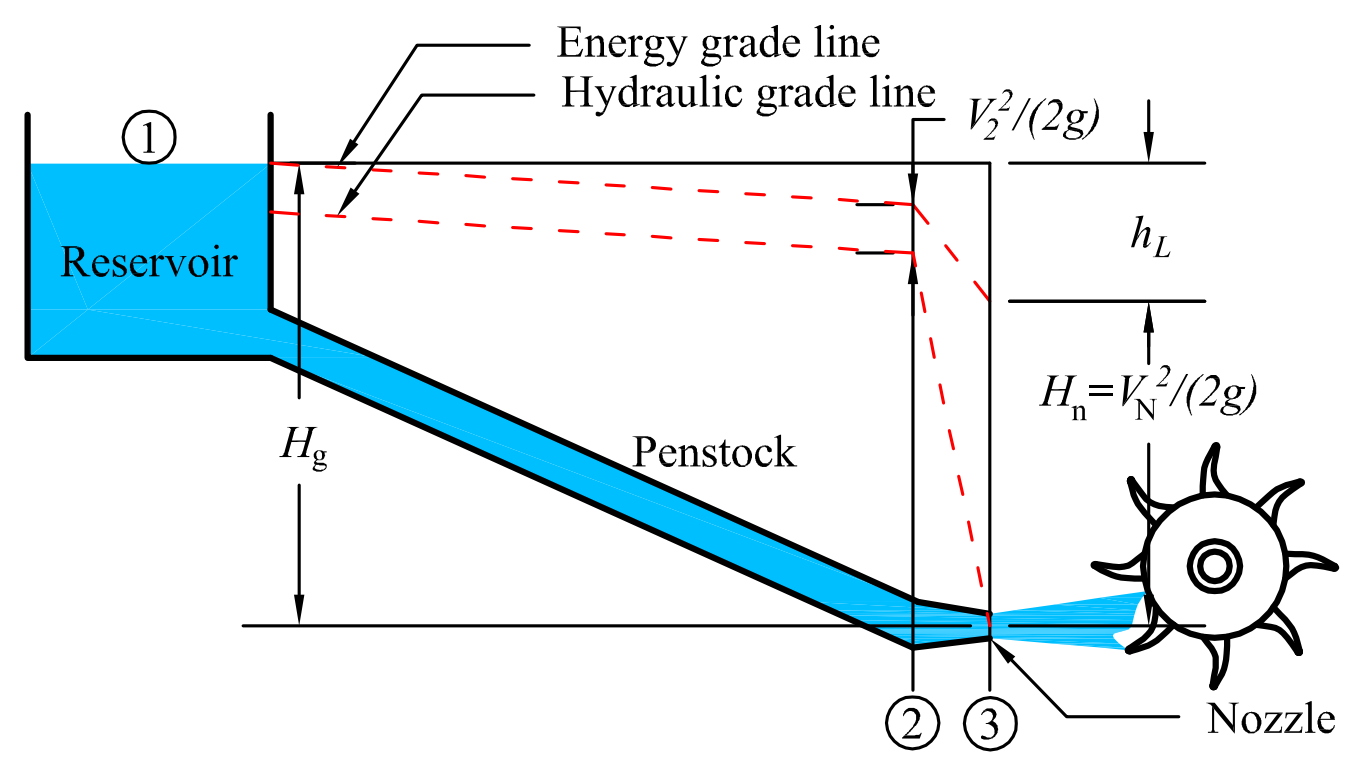

Fig. 1. Sketch of an impulse turbine

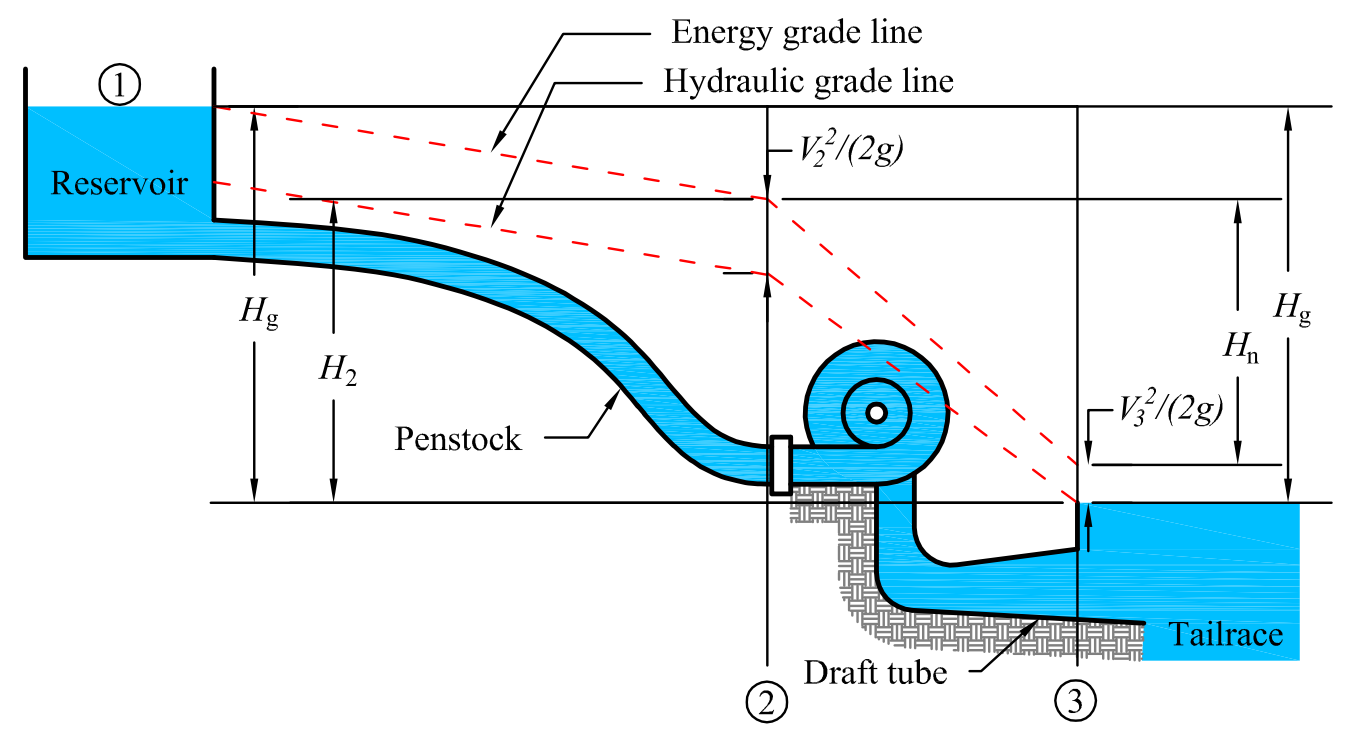

Fig. 2. Sketch of a reaction turbine

71 For a reaction turbine (see Fig. 2), the sum of head losses can be written as

$$
h_{L}=\frac{Q^{2}}{2 g A_{2}^{2}}\left[f \frac{L}{D_{2}}+\sum k_{1-2}+\left(\frac{A_{2}}{A_{d}}\right)^{2}\right]
$$


where $A_{d}$ is draft tube cross-sectional area at its outlet (section 3 in Fig. 2).

The expression inside the brackets in Eqs. (2) and (4) is dimensionless and it is denoted herein as

$$
C_{L}= \begin{cases}f \frac{L}{D_{2}}+\sum k_{1-2}+k_{N}\left(\frac{A_{2}}{A_{N}}\right)^{2} & \text { for an impulse turbine } \\ f \frac{L}{D_{2}}+\sum k_{1-2}+\left(\frac{A_{2}}{A_{d}}\right)^{2} & \text { for a reaction turbine }\end{cases}
$$

Hence, the total head losses in Eq. (2) and Eq. (4) is equal to the product of $C_{L}$ and $Q^{2} /\left(2 g A_{2}^{2}\right)$ and thus, Eq. (1) can be written as

$$
P=\eta \gamma Q\left(H_{g}-C_{L} \frac{Q^{2}}{2 g A_{2}^{2}}\right)
$$

For generalizing the findings in this paper, a dimensionless relationship between power and flow discharge is sought. To achieve this, Eq. (6) is divided by a reference power $\left(P_{r}\right) . P_{r}$ is assumed to be the maximum power that can be generated using a reference discharge $\left(Q_{r}\right)$ and a fixed gross head and penstock geometry (constant $C_{L}$ ). For maximum power, the turbine and generator efficiencies need to be $100 \%$ (i.e., $\eta_{t}=100 \%$ and $\eta_{g}=100 \%$ ). Also, maximum power for a fixed penstock geometry can be obtained by setting $d P / d Q$ in Eq. (6) equal to zero, which gives

$$
h_{L}=\frac{H_{g}}{3}
$$

84 turbine, which gives:

$$
Q_{r}=2 A_{3} \sqrt{\frac{1}{3} g H_{g}}
$$

${ }_{85}$ where $A_{3}$ is the cross-sectional area at section 3 in Figs. 1 and 2, given by

$$
A_{3}= \begin{cases}A_{N} & \text { for an impulse turbine } \\ A_{d} & \text { for a reaction turbine }\end{cases}
$$

$86 \quad$ Substituting Eq. (7) and Eq. (8) into Eq. (1) gives the following relation for the reference power $\left(P_{r}\right)$

$$
P_{r}=\frac{4}{3} \gamma H_{g} A_{3} \sqrt{\frac{1}{3} g H_{g}}
$$

Note that $Q_{r}$ and $P_{r}$ (Eqs. 8 and 10) are a function of the penstock properties and the gross head only. 88 Dividing each side of Eq. (6) by $P_{r}$ (Eq. 10) and defining $P / P_{r}$ as $P_{+}$and $Q / Q_{r}$ as $Q_{+}$, and after some 89 algebra, the following dimensionless relationship between power and discharge is obtained

$$
P_{+}=\eta\left[\frac{3}{2} Q_{+}-C_{L}\left(\frac{A_{3}}{A_{2}}\right)^{2} Q_{+}^{3}\right]
$$

90 Denoting with $\beta$ the product of $C_{L}$ and $\left(A_{3} / A_{2}\right)^{2}$, Eq. (11) can be rewritten as

$$
P_{+}=\eta\left(\frac{3}{2} Q_{+}-\beta Q_{+}^{3}\right)
$$

$91 \quad$ where

$$
\beta= \begin{cases}\left(\frac{A_{N}}{A_{2}}\right)^{2}\left(f \frac{L}{D_{2}}+\sum k_{1-2}+k_{N}\left(\frac{A_{2}}{A_{N}}\right)^{2}\right) & \text { for an impulse turbine } \\ \left(\frac{A_{d}}{A_{2}}\right)^{2}\left(f \frac{L}{D_{2}}+\sum k_{1-2}+\left(\frac{A_{2}}{A_{d}}\right)^{2}\right) & \text { for a reaction turbine }\end{cases}
$$

In practice, the ratios $A_{N} / A_{2}$ and $A_{d} / A_{2}$ in Eq. (13) are typically kept constant, which means that $\beta$ varies 93 as a function of $f, L, D_{2}$, and the coefficients of local head losses $\left(\sum k\right)$. In many applications, friction losses 
94 are more important than local head losses, that is $f \frac{L}{D_{2}} \gg \sum k$. Also, $L$ is typically constant as it is restricted 95 by topographic conditions. In addition, $f$ does not show significant variation as a function of discharge or ${ }_{96}$ penstock diameter. Let's recall that for a given penstock diameter, $f$ is independent of the Reynolds number 97 for fully developed turbulent flows, which is the case of most penstock flows. Hence, $\beta$ is more or less ${ }_{98}$ inversely proportional to the penstock diameter, $D_{2} \propto 1 / \beta$.

The variation of $P_{+}$with respect to $Q_{+}$for a fixed $\beta$ can be obtained by differentiating $P_{+}$with respect 100 to $Q_{+}$in Eq. (12), which gives

$$
\frac{d P_{+}}{d Q_{+}}=\eta\left(\frac{3}{2}-3 \beta Q_{+}^{2}\right)
$$

The maximum dimensionless power for a fixed $\beta$ can be obtained by setting $d P_{+} / d Q_{+}$in Eq. (14) equal to zero. The maximum power occurs when

$$
\left(Q_{+}\right)_{\max }=\sqrt{\frac{1}{2 \beta}}
$$

$$
\left(P_{+}\right)_{\max }=\eta \sqrt{\frac{1}{2 \beta}}
$$

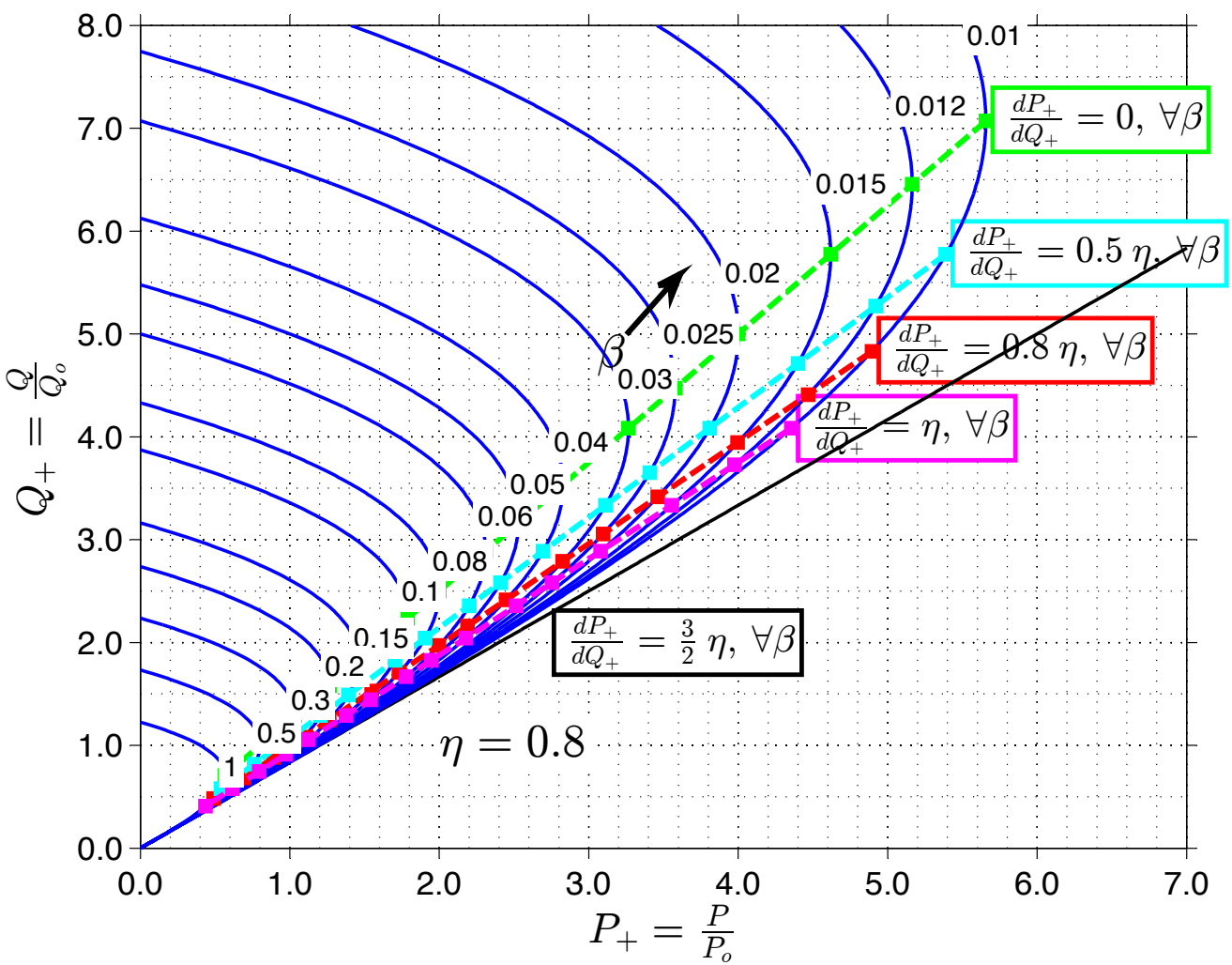

Fig. 3. Dimensionless discharge $\left(Q_{+}\right)$versus dimensionless power $\left(P_{+}\right)$for $\eta=0.8$ and a typical range of $\beta$ for impulse turbines 


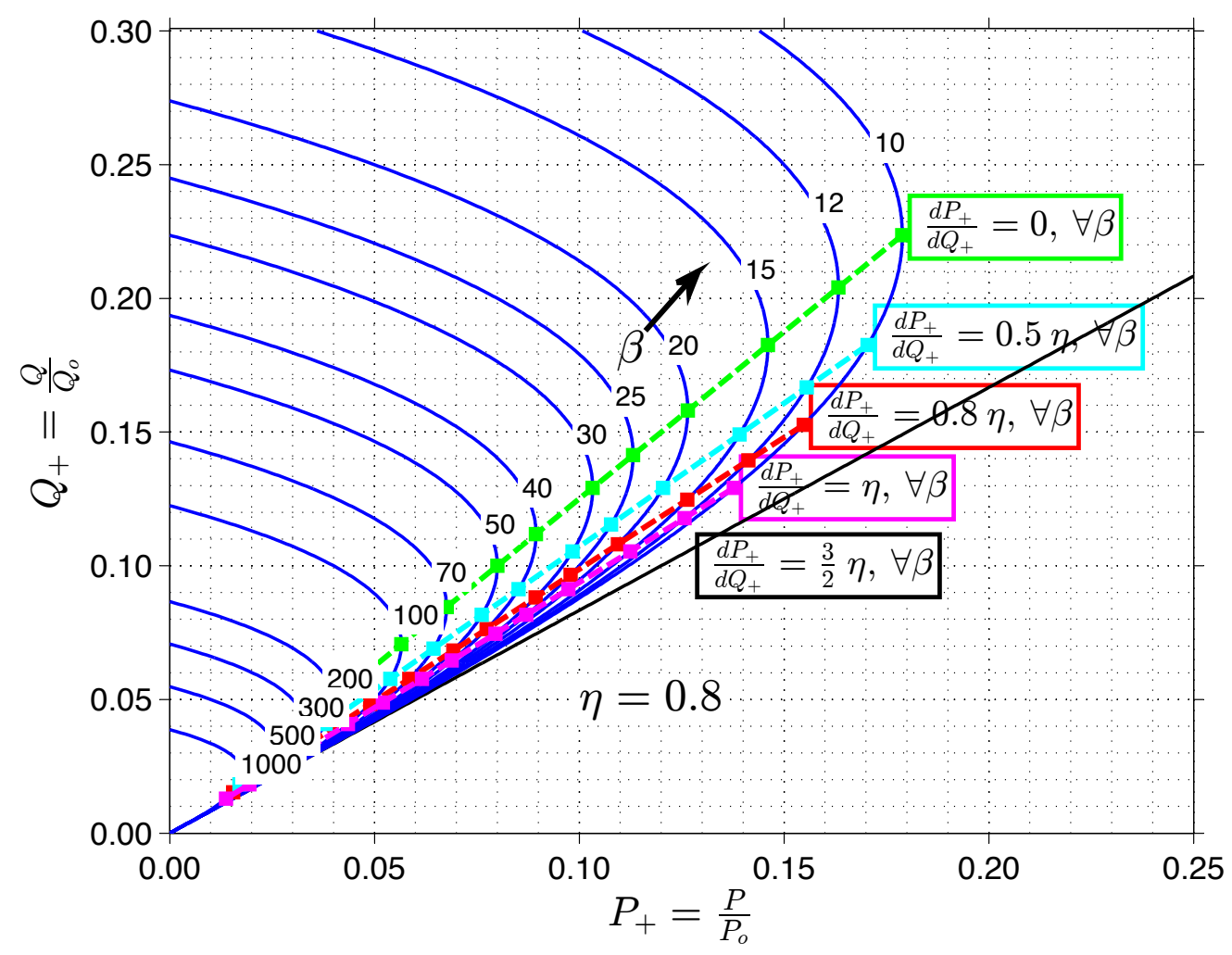

Fig. 4. Dimensionless discharge $\left(Q_{+}\right)$versus dimensionless power $\left(P_{+}\right)$for $\eta=0.8$ and a typical range of $\beta$ for reaction turbines

In most applications, $\beta$ should range between 0.01 and 1.0 for impulse turbines, and between 10 and 1000 for reaction turbines. Likewise, $C_{L}$ should range between 1 and 100 for both, impulse and reaction turbines. Even though $\beta$ is used throughout the entire paper, only $C_{L}$ is needed for design purposes.

Figures (3) and (4) plot $Q_{+}$versus $P_{+}$in Eq. (12) for typical ranges of $\beta$ for impulse and reaction turbines, respectively. An overall hydroelectric unit efficiency $(\eta)$ of 0.8 was used for plotting these figures. As can be observed in Figs. 3 and 4 , the change in power production in relation to change in flow discharge $\left(\Delta P_{+} / \Delta Q_{+}\right)$ for each dimensionless curve has a positive and negative gradient. For optimizing power production, only the positive gradient is of interest $\left(\Delta P_{+} / \Delta Q_{+}>0\right)$.

To visualize changes in power production in relation to changes in flow discharge, five ratios of $d P_{+} / d Q_{+}$ in Eq. (14) are plotted in Figs. 3 and 4 . Note in Figs. 3 and 4 that for a given $\beta$, the positive range of $d P_{+} / d Q_{+}$ varies from (3/2) $\eta$ to 0 . Note also that $d P_{+} / d Q_{+}$changes rapidly near $\left(Q_{+}\right)_{\max }$ and, that in the positive range of $d P_{+} / d Q_{+}$, the maximum relative power $P_{+}$occurs for the maximum relative flow discharge $Q_{+}$.

For minimizing water consumption to produce a given amount of hydropower, it is necessary that $d P_{+} / d Q_{+}$in Eq. (14) is close to its maximum value (3/2) $\eta$. Note in Figs. 3 and 4 that for each curve between approximately $d P_{+} / d Q_{+}=(3 / 2) \eta$ and $d P_{+} / d Q_{+}=0.8 \eta$, the increase in dimensionless power $\left(P_{+}\right)$ is approximately linear with increase in dimensionless discharge $\left(Q_{+}\right)$. Note also in these Figures that for $d P_{+} / d Q_{+}$smaller than about $0.8 \eta$, the increase in $P_{+}$is small compared to the increase in $Q_{+}$. Herein, to minimize water consumption, the optimal lower limit of $d P_{+} / d Q_{+}$is set to $0.8 \eta$.

Substituting $d P_{+} / d Q_{+}=0.8 \eta$ into Eq. (14) gives the following upper limit for the dimensionless flow 


$$
\left(Q_{+}\right)_{\text {opt upper }}=\sqrt{\frac{7}{30 \beta}}
$$

The corresponding upper limit for the dimensionless power is

$$
\left(P_{+}\right)_{\text {opt upper }}=\eta \frac{19}{15} \sqrt{\frac{7}{30 \beta}}
$$

Hence, the optimal dimensionless discharge range is $Q_{+} \in[0, \sqrt{7 /(30 \beta)}]$. The corresponding optimal dimensionless power range is $P_{+} \in\left[0, \eta \frac{19}{15} \sqrt{\frac{7}{30 \beta}}\right]$.

The optimal dimensionless head loss $\left(h_{L+}=h_{L} / H_{g}\right)$ can be obtained by assuming that the optimal upper limit for the flow discharge is $Q_{+}=\sqrt{7 /(30 \beta)}$ (Eq. 17). In Eq. (12), dividing the second term of the right-hand side (RHS) by the first term of the RHS gives

$$
h_{L+} \leq \frac{2}{3} \beta Q_{+}^{2}
$$

Substituting $\left(Q_{+}\right)_{\text {opt upper }}=\sqrt{7 /(30 \beta)}$ into Eq. (19) gives

$$
h_{L+} \leq \frac{7}{45}
$$

Eq. (20) shows that for minimizing water consumption, the ratio of head loss to gross head $\left(h_{L+}=\right.$ $h_{L} / H_{g}$ ) should not exceed $15.6 \%$. The $15.6 \%$ ratio also provides the threshold for the optimal penstock diameter. Losses higher than $15.6 \%$ mean that a small penstock diameter is used. The $15.6 \%$ ratio is about half of that derived for maximum power and maximum flow discharge, which is $33.3 \%$. This means that the optimal conditions for producing power do not correspond to those that use maximum flow discharge for a given $\beta$. This can be better understood by observing Figs. 3 and 4 , in which $d P_{+} / d Q_{+}$decreases rapidly near $\left(P_{+}\right)_{\max }$ for all $\beta$.

So far the analysis assumed that $\beta$ is constant and hence, the penstock diameter $\left(D_{2}\right)$. Following, the influence of changing the penstock diameter on power production is assessed. Earlier, it was argued that $D_{2}$ and $\beta$ are more or less inversely proportional. For example, reducing $\beta$ in half is approximately equivalent to doubling the penstock diameter. An increase in penstock diameter in turn results in a decrease in head losses and hence, an increase in power. For estimating the variation of $P_{+}$with respect to $\beta\left(\Delta P_{+} / \Delta \beta\right), Q_{+}$ in Eq. (12) is kept constant, which gives

$$
\frac{\Delta P_{+}}{\Delta \beta}=-\eta Q_{+}^{3}
$$

By combining Eqs. (12) and (21), and after some algebra, the following relationship between $\Delta P_{+} / P_{+}$ and $\Delta \beta / \beta$ is obtained

$$
\frac{\Delta P_{+}}{P_{+}}=-\frac{\Delta \beta}{\beta}\left(\frac{\beta Q_{+}^{3}}{\frac{3}{2} Q_{+}-\beta Q_{+}^{3}}\right)
$$

Note in Eq. (22) that the maximum relative power increase $\left(\Delta P_{+} / P_{+}\right)_{\max }$ incr will occur when $\Delta \beta / \beta=-1$, which would take place in the hypothetical case that $\beta$ is reduced to zero. The relationship between $\beta$ and $Q_{+}$when $d P_{+} / d Q_{+}=0$ can be obtained from Eq. (15), which gives $\beta=1 /\left(2\left(Q_{+}\right)_{\max }^{2}\right)$. By substituting this $\beta$ into Eq. (22), and using $\Delta \beta / \beta=-1$, gives $\left(\Delta P_{+} / P_{+}\right)_{\max }$ incr $=1 / 2$. Likewise an increase in $\beta$ will result in a decrease in power. It should be noted that the maximum relative power decrease $\left(\Delta P_{+} / P_{+}\right)_{\max }$ decr is $\Delta P_{+} / P_{+}=-1$, which would occur in the case that $P_{+}$is reduced to zero.

Figs. 5 and 6 plot the variation of $\Delta P_{+} / P_{+}$versus $\Delta \beta / \beta$ for two different values of $Q_{+}$(i.e., 0.06 and 3 ). 


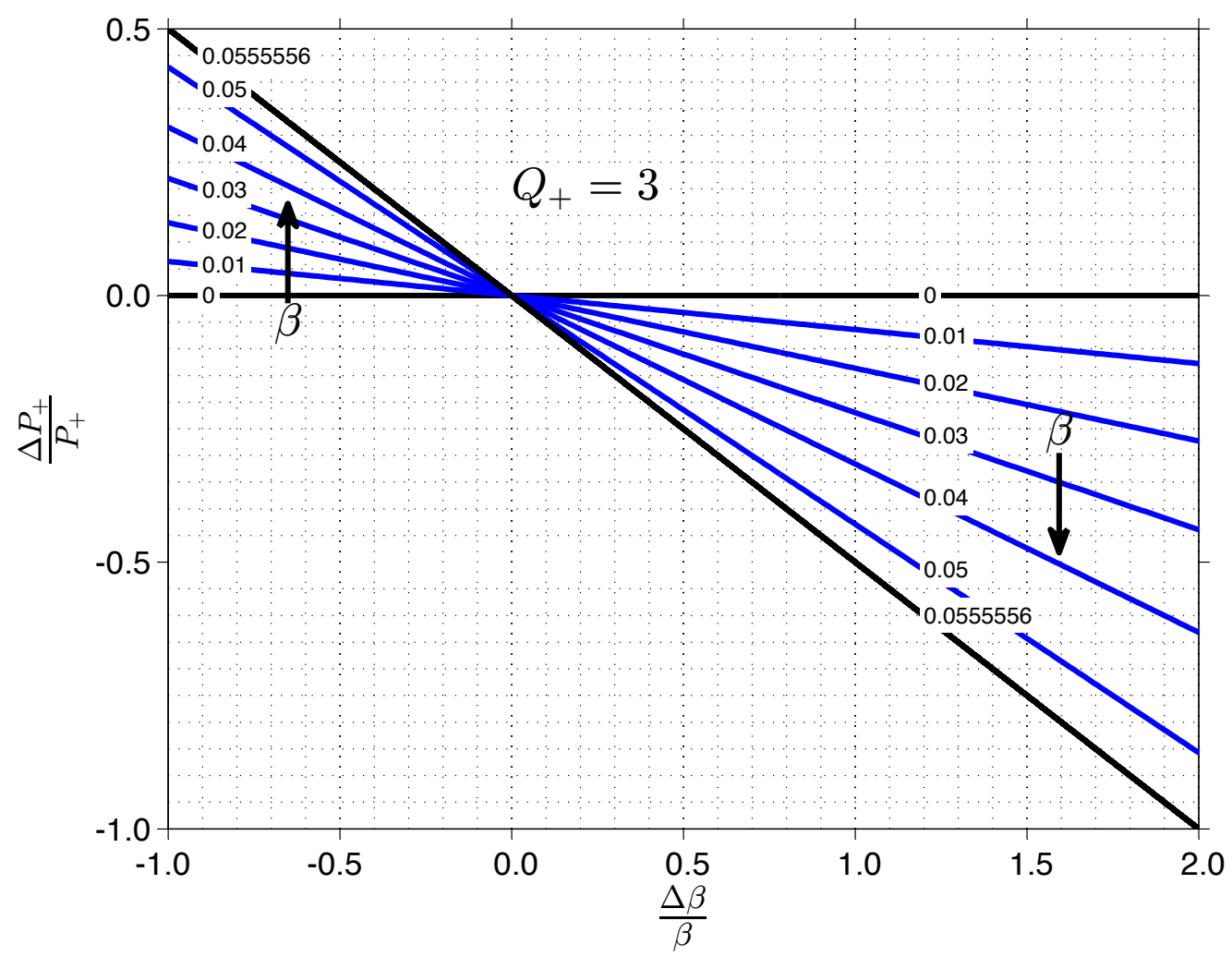

Fig. 5. $\Delta P_{+} / P_{+}$versus $\Delta \beta / \beta$ for $Q_{+}=3$

When designing a turbine, it is necessary to specify either the flow discharge to use or the desired electric power. These cases are presented below:

The larger value of $Q_{+}$(i.e., $Q_{+}=3$ ) is typical of an impulse turbine, while the smaller value (i.e., $Q_{+}=$ $0.06)$ corresponds to that of a reaction turbine. Note in Figs. 5 and 6 that relative power is increased when $\beta$ is reduced and viceversa.

For the assumed optimal flow conditions (see Eqs. 17 - 20), the maximum relative power increase can be obtained by substituting $\left(Q_{+}\right)_{\text {opt upper }}=\sqrt{7 /(30 \beta)}$ (Eq. 17) and $\Delta \beta / \beta=-1$ into Eq. (22), which gives $\Delta P_{+} / P_{+}$ $=18.4 \%$. If $\beta$ is reduced in half ( $D_{2}$ is approximately doubled), $\Delta P_{+} / P_{+}=9.2 \%$. In other words, for the assumed optimal flow conditions, a gain of about $9 \%$ in power production can be attained by doubling the penstock diameter.

For practical applications, the derived dimensionless relationships are made non-dimensionless. For instance, the optimal upper limit of the flow discharge can be obtained by combining Eqs. (8) and (17), which after some algebra gives

$$
Q_{\mathrm{opt}}=\frac{2}{3} A_{2} \sqrt{\frac{7}{10} \frac{g H_{g}}{C_{L}}}
$$

Similarly, the optimal upper limit of the power can be obtained by combining Eqs. (10) and (18), which after some algebra gives

$$
P_{\mathrm{opt}}=\frac{76}{135} \eta \gamma H_{g} A_{2} \sqrt{\frac{7}{10} \frac{g H_{g}}{C_{L}}}
$$




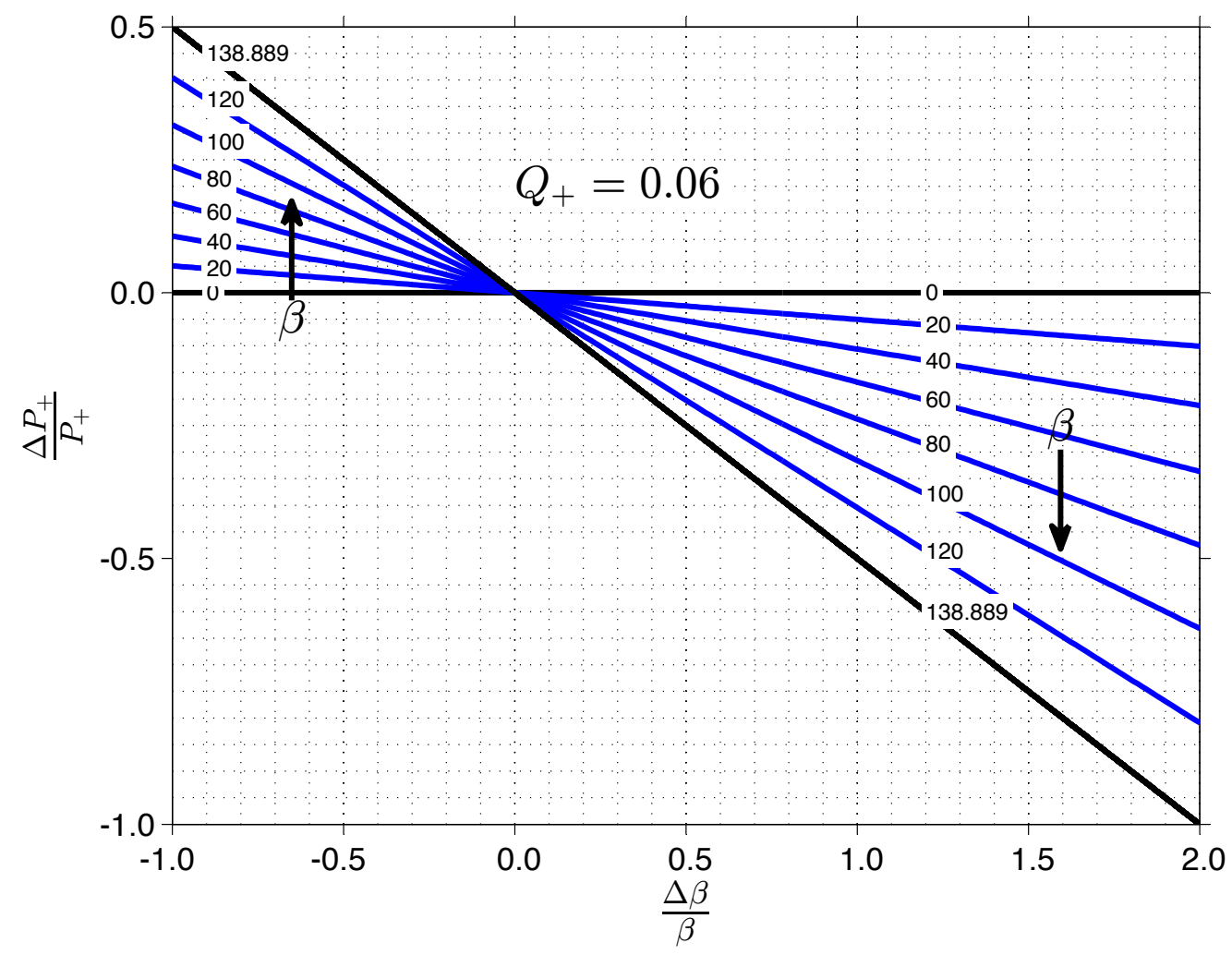

Fig. 6. $\Delta P_{+} / P_{+}$versus $\Delta \beta / \beta$ for $Q_{+}=0.06$

\section{1. $P$ is specified}

If $P$ is specified, the optimal upper limit of the flow discharge can be obtained by combining Eqs. (23) and (24), which gives

$$
Q_{\mathrm{opt}}=\frac{45}{38}\left(\frac{P}{\eta \gamma H_{g}}\right)
$$

The optimal penstock diameter can be determined from Eq. (23) as follows

$$
\frac{\left(C_{L}\right)_{\mathrm{opt}}}{A_{2}^{2}} \leq \frac{14}{45} \frac{g H_{g}}{Q^{2}}
$$

where $Q$ in Eq. (26) is the same as that in Eq. (25).

\section{2. $Q$ is specified}

If $Q$ is specified, the optimal upper limit of the power can be obtained by combining Eqs. (23) and (24), which gives

$$
P_{\text {opt }}=\frac{38}{45} \eta \gamma H_{g} Q
$$

In this case, the optimal penstock diameter can still be determined using Eq. (26).

It is pointed out that the proposed methodology for determining the optimal flow discharge and optimal penstock diameter does not account for cavitation. Reaction turbines (not impulse turbines) are subjected to cavitation. In reaction turbines, cavitation may occur at the outlet of the runner or at the inlet of the draft 
tube where the pressure is considerably reduced (Dixon 2005). In order to determine whether cavitation will occur in any portion of a reaction turbine, the Thoma's cavitation factor $(\sigma)$ is compared with the critical cavitation factor $\left(\sigma_{c}\right)$. If the value of $\sigma$ is greater than $\sigma_{c}$ cavitation will not occur in the turbine under analysis, where $\sigma_{c}$ is a function of the specific speed of the turbine $\left(N_{s}\right)$. Because $N_{s}$ is not used in the proposed methodology, the occurrence of cavitation cannot be determined using the utilized parameters. The occurrence of cavitation in reaction turbines needs be checked after using the proposed methodology.

Following two examples of application for determining optimal flow discharge and optimal penstock diameter for an impulse turbine and a reaction turbine are presented.

\section{Example of application for an impulse turbine}

The site, penstock and nozzle characteristics for this example are as follows:

1. Gross head $\left(H_{g}\right)=200 \mathrm{~m}$

2. Penstock length $(L)=500 \mathrm{~m}$

3. Ratio of penstock cross-sectional area to nozzle cross-sectional area at its outlet $\left(A_{2} / A_{N}\right)=16$

4. Nozzle velocity coefficient $\left(C_{V}\right)=0.985$

5. Sum of local losses in penstock due to entrance, bends, penstock fittings and gates $\left(\sum k_{1-2}\right)=1.5$

6. Roughness height of penstock material $(\epsilon)=0.045 \mathrm{~mm}$ (commercial steel)

7. Kinematic Viscosity $(v)=10^{-6} \mathrm{~m}^{2} / \mathrm{s}$

8. Turbine efficiency $\left(\eta_{t}\right)=82 \%$

9. Generator efficiency $\left(\eta_{g}\right)=90 \%$

\subsection{Case A1: $Q$ is specified}

In this case, let's assume that the design flow $Q$ is $0.6 \mathrm{~m}^{3} / \mathrm{s}$ and it is desired to know the optimal hydropower that can be extracted using this flow. First, it is necessary to determine the optimal penstock diameter. From Eq. (26),

$$
\frac{\left(C_{L}\right)_{\mathrm{opt}}}{A_{2}^{2}}=1693.8272 \mathrm{~m}^{-4}
$$

204 where $C_{L}=500 f / D_{2}+1.5+k_{N}\left(16^{2}\right)$.

The nozzle coefficient is determined using Eq. (3), which gives $k_{N}=0.0307$. The friction factor $(f)$ is determined using the explicit Swamee-Jain equation which is given by

$$
f=\frac{0.25}{\left[\log _{10}\left(\frac{\epsilon}{3.7 D_{2}}+\frac{5.74}{\operatorname{Re}^{0.9}}\right)\right]^{2}}
$$

where $\epsilon$ is the roughness height and Re is the Reynolds number. The Reynolds number is defined as $V D_{2} / v$, where $V$ is the flow velocity. Note that when $Q$ is known, $f$ and $C_{L}$ are functions of $D_{2}$ only. Solving for $D_{2}$ in the above relation of $\left(C_{L}\right)_{\text {opt }} /\left(A_{2}^{2}\right)$ gives $D_{2}=0.3968 \mathrm{~m}$. In practice, a penstock with an internal diameter equal or slightly larger than $0.3968 \mathrm{~m}(397 \mathrm{~mm})$ would be selected. Assuming that a schedule 80 steel pipe is required due to structural considerations, a 18 in outside diameter pipe would be selected. For this pipe, the wall thickness is 0.938 in, and hence the internal diameter is 16.124 in $(409.5 \mathrm{~mm})$. For this pipe diameter, the value of $C_{L}$ is 25.35 . This value can be used to determine the dimensionless head loss as follows (e.g., second and first terms in Eq. (6), respectively).

$$
h_{L+}=C_{L} \frac{Q^{2}}{2 g H_{g} A_{2}^{2}}=0.134 \text { or } 13.4 \%
$$

215 which satisfies the inequality in Eq. (20) $[<15.6 \%]$. 
The electric power that can be extracted from this system can be determined using Eq. (6), which gives,

$$
P=0.82 \times 0.90 \times 1000 \times 9.8 \times 0.6 \times\left(200-25.35 \times \frac{0.6^{2}}{2 \times 9.8 \times 0.1317^{2}}\right)=751421 \mathrm{~W}=751.4 \mathrm{~kW}
$$

To facilitate the calculations, a Matlab hydropower calculator was developed which Graphical User Interface (GUI) is shown in Fig. 7. As can be observed in this Figure, the consumption of flow is optimized in the linear region because the amount of power is proportional to the amount of flow used. Right before the the high positive gradient in each curve, both the flow discharge and the penstock diameter are optimized. The hydropower calculator is available at http://web.engr.oregonstate.edu/ leon/Codes/ Hydropower/.

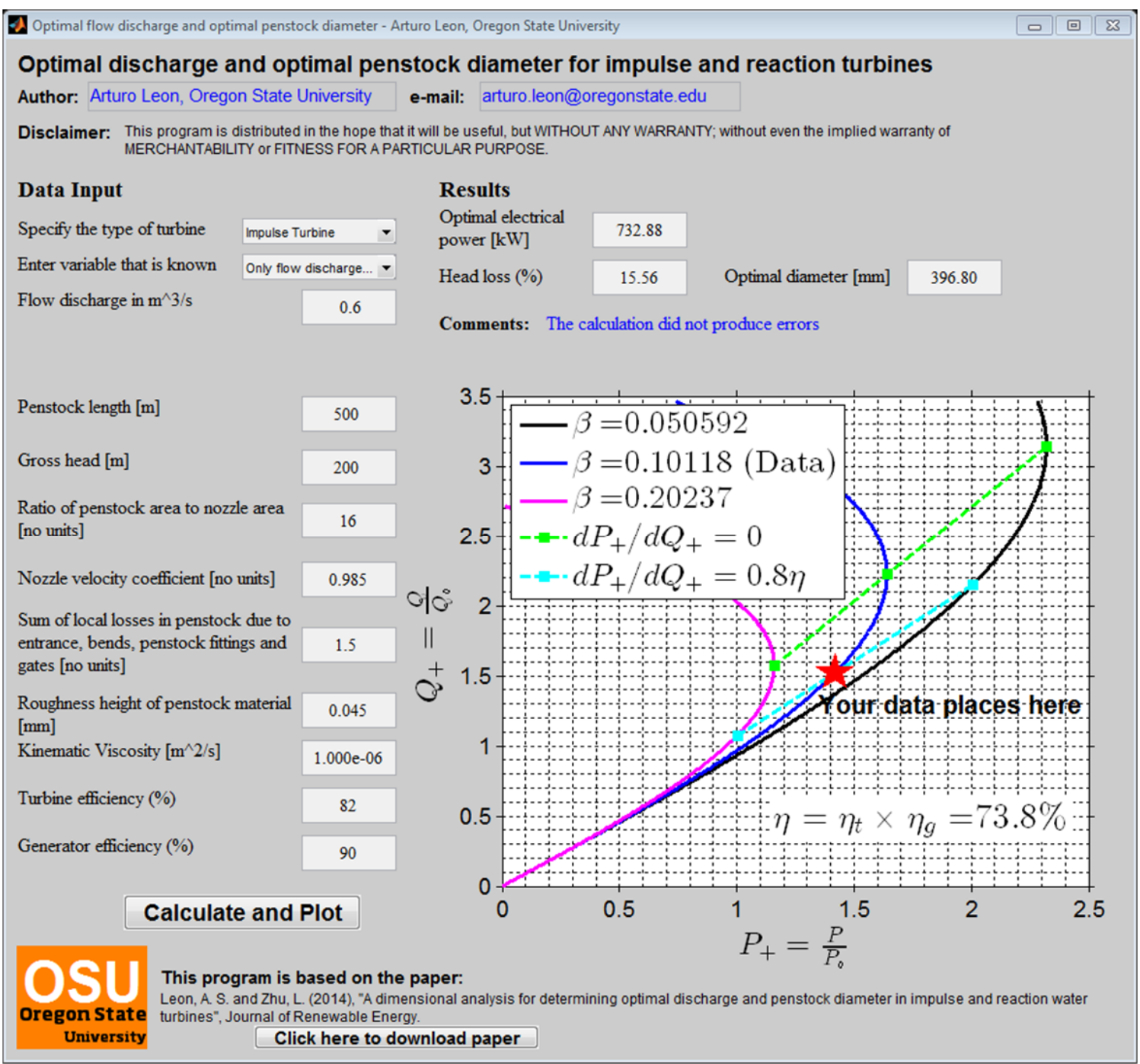

Fig. 7. Graphical User Interface (GUI) of hydropower calculator 
3.2. Case B1: P is specified

In this case, assume that $P$ is $100 \mathrm{~kW}$ and it is desired to determine the optimal flow discharge and optimal penstock diameter to produce this power. In this case, first, the optimal discharge is determined using Eq. (25) as follows:

$$
Q_{\text {opt }}=\frac{45}{38}\left(\frac{100,000}{0.82 \times 0.90 \times 1000 \times 9.8 \times 200}\right)=0.082 \mathrm{~m}^{3} / \mathrm{s}(82 \mathrm{~L} / \mathrm{s})
$$

The optimal pipe diameter (inside diameter) can de determined in a similar way to Case Al, which gives $0.176 \mathrm{~m}$

\section{Example of application for a reaction turbine}

The site and penstock characteristics for this example are the same as those of the impulse turbine example. A new parameter for this example is

1. Ratio of penstock cross-sectional area to draft tube cross-sectional area at its outlet $\left(A_{2} / A_{d}\right)=1 / 3$

\subsection{Case A2: $Q$ is specified}

As in the case of an impulse turbine, assume that the design flow $Q$ is $0.6 \mathrm{~m}^{3} / \mathrm{s}$ and it is desired to determine the optimal penstock diameter, and the optimal electric power that can be extracted using this flow. First, it is necessary to determine the optimal penstock diameter. From Eq. (26),

$$
\frac{\left(C_{L}\right)_{\mathrm{opt}}}{A_{2}^{2}}=1693.8272 \mathrm{~m}^{-4}
$$

where $C_{L}=500 f / D_{2}+1.5+(1 / 3)^{2}$.

In a similar manner to case $\mathrm{A} 1$, solving for $D_{2}$ in the above relation of $\left(C_{L}\right)_{\text {opt }} /\left(A_{2}^{2}\right)$ gives $D_{2}=0.3696$ $\mathrm{m}$. Assuming again that a schedule 80 steel pipe is required due to structural considerations, a 18 in outside diameter pipe would be selected. For this pipe, the wall thickness is 0.938 in, and hence the internal diameter is 16.124 in $(409.5 \mathrm{~mm})$. For this pipe diameter, the value of $C_{L}$ is 17.60 . Again, this value can be used to determine the dimensionless head loss, which gives 9.3\%. This dimensionless head loss satisfies the inequality in Eq. $(20)(<15.6 \%)$. The electric power that can be extracted from this system can be determined using Eq. (6), which gives $787.01 \mathrm{~kW}$, which in turn is slightly larger than that determined using an impulse turbine and the same flow discharge.

\subsection{Case B2: P is specified}

As in the case of an impulse turbine, assume that $P$ is $100 \mathrm{~kW}$ and it is desired to determine the optimal flow discharge and optimal penstock diameter to produce this power. In this case, the optimal discharge is determined using Eq. (25), which gives $82 \mathrm{~L} / \mathrm{s}$. After the optimal flow discharge has been determined, a similar procedure to Case $A 2$ can be followed to determine the optimal pipe inside diameter. The optimal pipe inside diameter results in $0.171 \mathrm{~m}$. This diameter is slightly smaller than that found for an impulse turbine and for the same flow discharge.

\section{Conclusions}

This paper presents a dimensional analysis for determining optimal flow discharge and optimal penstock diameter when designing impulse and reaction turbines for hydropower systems. The aim of this analysis is to provide general insights for minimizing water consumption when producing hydropower. The key findings are as follows:

1. The analysis is based on the geometric and hydraulic characteristics of the penstock, the total hydraulic head, and the desired power production. 
2. This analysis resulted in various dimensionless relationships between power production, flow discharge and head losses.

3. The derived relationships were used to withdraw general insights on determining optimal flow discharge and optimal penstock diameter. For instance, it was found that for minimizing water consumption, the ratio of head loss to gross head $\left(h_{L} / H_{g}\right)$ should not exceed about $15 \%$.

4. To facilitate the calculations, a Matlab hydropower calculator was developed which is available at http://web.engr.oregonstate.edu/ leon/Codes/Hydropower/.

5. Overall, the present analysis is general and can be used for determining optimal design flow and penstock diameter when designing impulse and reaction turbines.

\section{Acknowledgments}

The authors gratefully acknowledge the financial support of the Bonneville Power Administration of the U.S. Department of Energy (DOE) under award number TIP\#258.

\section{Notation}

The following symbols are used in this paper:

$A_{2}=$ penstock cross-sectional area;

$A_{d}=$ draft tube cross-sectional area at its outlet;

$A_{N}=$ nozzle cross-sectional area;

$C_{V}=$ Nozzle velocity coefficient;

$C_{L}=$ dimensionless parameter that is function of penstock properties only;

$D_{2}=$ penstock diameter;

$g=$ acceleration due to gravity;

$H_{g}=$ gross head;

$h_{L}=$ sum of head losses;

$k_{N}=$ nozzle head loss coefficient;

$L=$ Penstock length;

$P_{r}=$ reference power;

$P_{+}=P / P_{r}$;

$Q=$ flow discharge;

$Q_{r}=$ reference flow discharge;

$Q_{+}=Q / Q_{r}$;

$\beta=$ product of $C_{L}$ and $\left(A_{3} / A_{2}\right)^{2}$;

$\epsilon=$ roughness height;

$\eta=$ product of $\eta_{t}$ and $\eta_{g}$;

$\eta_{g}=$ Generator efficiency;

$\eta_{t}=$ Turbine efficiency;

$\gamma=$ Specific weight of water;

$v=$ Kinematic Viscosity;

$\sum k_{1-2}=$ Sum of local losses in penstock due to entrance, bends, pipe fittings and gates.

\section{References}

[1] Brater E F, King H W. Handbook of hydraulics, McGraw-Hill, New York; 1976

[2] Dixon S L. Fluid mechanics and thermodynamics of turbomachinery, 5th ed., Elsevier, Burlinton, Massachusetts, 2005.

[3] International Energy Agency Implementing Agreement for Hydropower Technologies and Programmes [IEA Hydro]. Hydropower and the world's energy future. The Role of hydropower in bringing clean, renewable energy to the world 2000. http: //www . ieahydro.org/reports/Hydrofut.pdf [accessed Nov. 30, 2013].

[4] Pelz P. Upper limit for hydropower in an open-channel flow. J. Hydraul. Eng. 2011; 137(11):1536-1542. 
[5] Schumann K, Saili L, Taylor R, Abdel-Malek R. Hydropower and sustainable development: A journey. Proc. 21st World Energy Congress ed. by World Energy Council; 2010 Sept.11-16, Montreal, CA. http://www . worldenergy . org/documents/ congresspapers/392.pdf [accessed Nov. 30, 2013].

[6] U.S. Energy Information Administration (USEIA). World energy demand and economic outlook. International Energy Outlook 2013. http://www.eia.doe.gov/oiaf/ieo/world.html [accessed Nov. 30, 2013].

[7] U.S. Institute for Energy Research [USIER]. Renewable energy in the U.S. Renew Energy 2013. http://www. instituteforenergyresearch.org/energy-overview/renewable-energy/\#_ednref 4 [accessed Nov. 30, 2013]. 